\title{
Autophosphorylation of $\alpha$ CaMKII is differentially involved in new learning and unlearning mechanisms of memory extinction
}

\author{
Ryoichi Kimura, ${ }^{1}$ Alcino J. Silva, ${ }^{2-4}$ and Masuo Ohno ${ }^{1,5}$ \\ ${ }^{1}$ Center for Dementia Research, Nathan Kline Institute, New York University School of Medicine, Orangeburg, New York 10962, \\ USA; ${ }^{2}$ Department of Neurobiology, Brain Research Institute, University of California, Los Angeles, Los Angeles, California \\ 90095-1761, USA; ${ }^{3}$ Department of Psychiatry, University of California, Los Angeles, Los Angeles, California 90095-1761, USA; \\ ${ }^{4}$ Department of Psychology, University of California, Los Angeles, Los Angeles, California 90095-1761, USA
}

\begin{abstract}
Accumulating evidence indicates the key role of $\alpha$-calcium/calmodulin-dependent protein kinase II ( $\alpha \mathrm{CaMKII)}$ in synaptic plasticity and learning, but it remains unclear how this kinase participates in the processing of memory extinction. Here, we investigated the mechanism by which $\alpha$ CaMKII may mediate extinction by using heterozygous knock-in mice with a targeted T286A mutation that prevents the autophosphorylation of this kinase $\left(\alpha \mathrm{CaMKII}{ }^{\mathrm{T} 286 \mathrm{~A}+/-}\right)$. Remarkably, partial reduction of $\alpha \mathrm{CaMKII}$ function due to the $\mathrm{T}^{286 \mathrm{~A}^{+/-}}$mutation prevented the development of extinction without interfering with initial hippocampus-dependent memory formation as assessed by contextual fear conditioning and the Morris water maze. It is hypothesized that the mechanism of extinction may differ depending on the interval at which extinction training is started, being more akin to "new learning" at longer intervals and "unlearning" or "erasure" at shorter intervals. Consistent with this hypothesis, we found that extinction conducted $24 \mathrm{~h}$, but not $15 \mathrm{~min}$, after contextual fear training showed spontaneous recovery (reappearance of extinguished freezing responses) $21 \mathrm{~d}$ following the extinction, representing behavioral evidence for new learning and unlearning mechanisms underlying extinction $24 \mathrm{~h}$ and $15 \mathrm{~min}$ post-training, respectively. Importantly, the $\alpha C a M K I I{ }^{\mathrm{T} 286 \mathrm{~A}+1-}$ mutation blocked new learning of contextual fear memory extinction, whereas it did not interfere with unlearning processes. Our results demonstrate a genetic dissociation of new learning and unlearning mechanisms of extinction, and suggest that $\boldsymbol{\alpha}$ CaMKII is responsible for extinguishing memories specifically through new learning mechanisms.
\end{abstract}

A growing body of evidence suggests that memory retrieval is a dynamic process that modifies stored information following initial learning. For example, if animals are given repeated or prolonged re-exposure to the conditioned stimulus (CS) without the unconditioned stimulus (US) after training with CS-US pairing(s) in Pavlovian fear conditioning, they exhibit memory extinction as measured by a decline in conditioned fear responses. Extinction is thought to be an active learning process resulting in new memories that compete with and suppress the expression of original memory ("new learning") (Myers and Davis 2002, 2007). Alternatively, extinction may simply reflect forgetting or erasing mechanisms of the original memory trace ("unlearning") (Myers and Davis 2002, 2007). Interestingly, recent studies have begun to reveal that these different mechanisms that underlie extinction occur depending on the length of time following fear acquisition (Cain et al. 2005; Mao et al. 2006; Myers et al. 2006). Extinction initiated shortly after acquisition preferentially engages unlearning processing, while extinction initiated at longer delays recruits a new learning mechanism as evidenced by the re-emergence of extinguished fear responses with the passage of time (spontaneous recovery), following unsignaled presentation of the US (reinstatement) or when tested in a context different from the one where extinction training takes place (renewal) (Myers et al. 2006). Although some, but not all, components of

\footnotetext{
${ }^{5}$ Corresponding author.
}

E-mail mohno@nki.rfmh.org; fax (845) 398-5422.

Article is online at http://www.learnmem.org/cgi/doi/10.1101//m.1049608. the molecular machinery required for initial memory formation are suggested to be involved in its extinction (Myers and Davis 2002, 2007), it remains unclear how the learning-related signaling is responsible for the two distinct mechanisms of memory extinction.

$\alpha$-Calcium/calmodulin-dependent protein kinase II ( $\alpha$ CaMKII) is an abundant synaptic protein that is central to memory formation (Irvine et al. 2006) and long-term potentiation (LTP), an activity-dependent strengthening of synapses that is thought to underlie learning and memory (Lisman et al. 2002). A broad range of genetic lesions of $\alpha$ CaMKII signaling has been demonstrated to block both learning and LTP (Elgersma et al. 2004). In particular, autophosphorylation of $\alpha$ CaMKII at threonine-286 in response to $\mathrm{Ca}^{2+}$ influx, which switches the kinase into a $\mathrm{Ca}^{2+} /$ calmodulin-independent or autonomously active state, provides a crucial step (Miller and Kennedy 1986; Fukunaga et al. 1995; Tan and Liang 1996; Ouyang et al. 1997; Rodrigues et al. 2004), since knock-in mice with a targeted point mutation (T286A) that prevents autophosphorylation at this site exhibit deficits in hippocampal LTP and memory formation (Giese et al. 1998; Ohno et al. 2002, 2005, 2006; Need and Giese 2003; Irvine et al. 2005; Cooke et al. 2006). Although the mechanisms by which $\alpha$ CaMKII autophosphorylation contributes to learning have been well documented, its role in memory extinction remains to be determined. Two pharmacological investigations demonstrated that extinction of step-down passive avoidance performance was impaired when rats received the CaMKII inhibitor KN-62 before the first extinction exposure (Szapiro et al. 2003; 
Bevilaqua et al. 2006), but the precise mechanism by which this kinase mediates memory extinction is poorly understood. To address this question, the present study was designed to test the impacts of the $\alpha$ CaMKII ${ }^{\mathrm{T} 286 \mathrm{~A}}$ point mutation on the extinction of hippocampus-dependent memory in contextual fear conditioning and Morris water maze paradigms, focusing on new learning and unlearning mechanisms. Although $\alpha \mathrm{CaMKII}^{\mathrm{T} 286 \mathrm{~A}}$ mice provide a valuable tool to study $\alpha$ CaMKII function in vivo, the homozygous T286A mutation significantly impairs hippocampal learning and precludes the analysis of extinction processes that follow the establishment of memory. Therefore, we investigated mice heterozygous for a T286A point mutation ( $\left.\alpha \mathrm{CaMKII}^{\mathrm{T} 286 \mathrm{~A}+/-}\right)$ that have partially reduced levels of $\alpha$ CaMKII function but retain normal learning abilities (Ohno et al. 2001), thus allowing us to specifically test their phenotypes during memory extinction.

\section{Results}

\section{The $\alpha \mathrm{CaMKII}{ }^{\mathrm{T} 286 \mathrm{~A}+/-}$ mutation blocks extinction of contextual fear memory}

Our previous study demonstrated that mice homozygous for an $\alpha \mathrm{CaMKII}^{\mathrm{T} 286 \mathrm{~A}}$ point mutation show impairments in hippocampus-dependent contextual fear conditioning, in which mice learn to associate a distinct context (CS) with an aversive foot shock (US) (Ohno et al. 2005). In contrast, heterozygous $\alpha \mathrm{CaMKII}^{\mathrm{T} 286 \mathrm{~A}+\text { - }}$ mice were normal in contextual learning, since they exhibited a robust contextual freezing response (the absence of all but respiratory movements) that was comparable to wildtype controls when tested $24 \mathrm{~h}$ after training with one CS-US pairing $\left(F_{(1,58)}=0.24, P>0.05\right)$ (Fig. 1). Furthermore, no difference was observed between $\alpha$ CaMKII ${ }^{\mathrm{T} 286 \mathrm{~A}+/-}$ and wild-type mice in levels of freezing before or after the foot shock during training sessions (data not shown), suggesting that $\alpha \mathrm{CaMKII}^{\mathrm{T} 286 \mathrm{~A}+/-} \mathrm{mu}-$ tants were also normal in movements and fear expression. During extinction, mice were repeatedly re-exposed to the conditioning chamber without a foot shock for $6 \mathrm{~min}$ per day for five consecutive days. Wild-type control mice showed a significant reduction in contextual freezing levels during the extinction sessions $\left(F_{(4,170)}=7.57, P<0.05\right)$. In contrast, repeated 6-min exposures to the conditioning chamber for $5 \mathrm{~d}$ did not affect contextual memory in $\alpha \mathrm{CaMKII}{ }^{\mathrm{T} 286 \mathrm{~A}+/-}$ mutants $\left(F_{(4,120)}=0.26\right.$, $P>0.05$ ) (Fig. 1A), and freezing levels of $\alpha \mathrm{CaMKII}{ }^{\mathrm{T} 286 \mathrm{~A}+/-}$ mice observed on Day 5 were significantly higher than those of wildtype littermate mice $\left(F_{(1,58)}=14.58, P<0.05\right)$ (Fig. 1B). Together, the $\alpha \mathrm{CaMKII}^{\mathrm{T} 286 \mathrm{~A}+/-}$ mutation specifically blocked extinction of contextually conditioned fear memory without affecting initial memory formation.

\section{$\alpha \mathrm{CaMKII}{ }^{\mathrm{T} 286 \mathrm{~A}+/-}$ mutation blocks extinction of spatial memory}

To address the role of $\alpha$ CaMKII signaling in extinguishing the different types of memory, we next tested $\alpha \mathrm{CaMKII}^{\mathrm{T} 286 \mathrm{~A}+/-}$ mice in the Morris water maze (Fig. 2). In the hidden platform version of the water maze, animals learn to locate a submerged platform in a pool filled with opaque water. This hippocampus-dependent spatial navigation performance is profoundly impaired in homozygous $\alpha \mathrm{CaMKII}^{\mathrm{T} 286 \mathrm{~A}}$ mutant mice (Giese et al. 1998; Need and Giese 2003; Ohno et al. 2005). In contrast, $\alpha$ CaMKII ${ }^{\mathrm{T} 286 \mathrm{~A}+/-}$ mice were normal in spatial learning in the water maze, since both the heterozygotes $\left(F_{(4,30)}=2.88, P<0.05\right)$ and wild-type controls $\left(F_{(4,70)}=10.62, P<0.05\right)$ showed similar reductions in their latencies to find the escape platform during acquisition (three sessions of two trials per day for $5 \mathrm{~d}$ ) (Fig. 2A). Twenty-four hours after the last training trial, mice received four consecutive probe trials (30-min intervals) in which the platform was removed and mice were allowed to search for it for $60 \mathrm{sec}$, and the effects of the $\alpha \mathrm{CaMKII}{ }^{\mathrm{T} 286 \mathrm{~A}+/-}$ mutation on the course of spatial memory extinction were examined. On the first probe test, both $\alpha \mathrm{CaMKII}{ }^{\mathrm{T} 286 \mathrm{~A}+1-}$ mutant $\left(F_{(3,24)}=3.45, P<0.05\right)$ and wild-type control $\left(F_{(3,56)}=3.71, P<0.05\right)$ mice spent a significantly longer time in the target quadrant where the hidden platform was during spatial training, as compared with the other three quadrants. No significant difference in the search performance on the first probe trial $\left(F_{(1,20)}=0.74, P>0.05\right)$ demonstrated that $\alpha$ CaMKII ${ }^{\mathrm{T} 286 \mathrm{~A}+/-}$ mice had normal spatial memory function (Fig. 2B).

Consistent with previous results (Lattal et al. 2003; Suzuki et al. 2004), repeatedly placing mice into the pool in the absence of the platform resulted in a decreased preference for the target quadrant in wild-type controls $\left(F_{(3,56)}=\right.$ 3.48, $P<0.05)$ (Fig. 2B). In contrast, $\alpha \mathrm{CaMKII}{ }^{\mathrm{T} 286 \mathrm{~A}+/-}$ mutants showed no reduction in the percentage of time spent in the target quadrant through four probe trials $\left(F_{(3,24)}=0.15, P>0.05\right)$, and their extinction rate of spatial memory was significantly lower than that of wild-type littermate controls $\left(F_{(1,20)}=21.31, P<0.05\right)$. Using another 
A
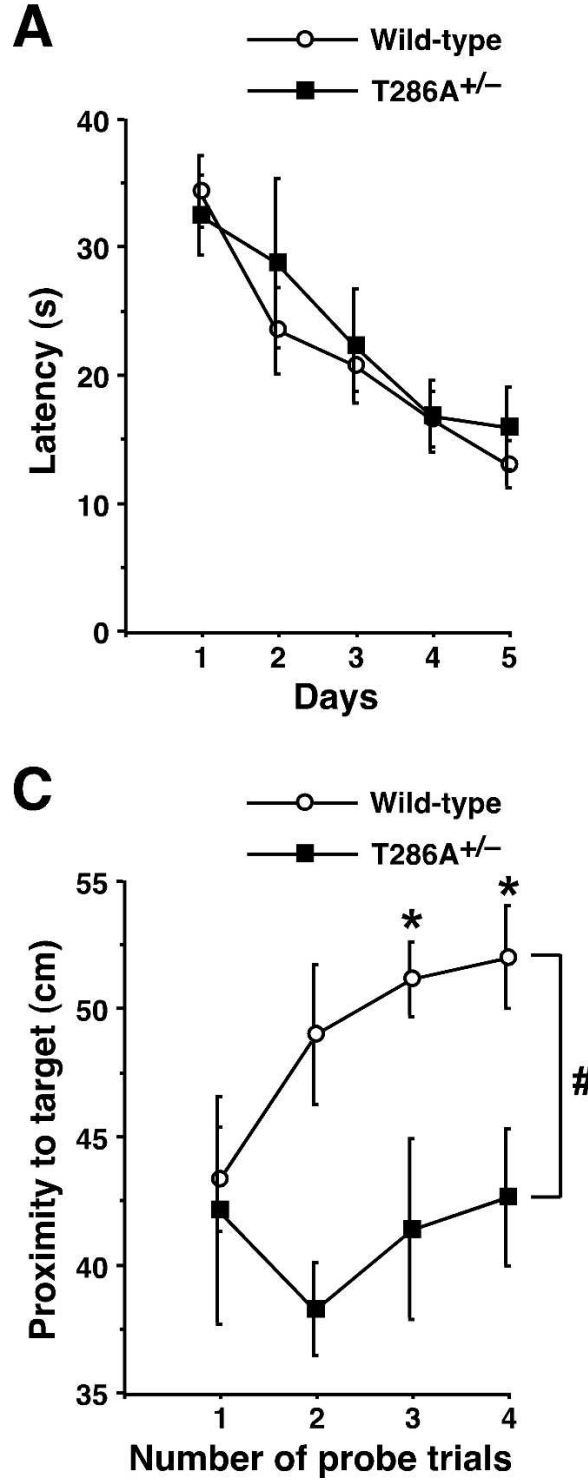

B
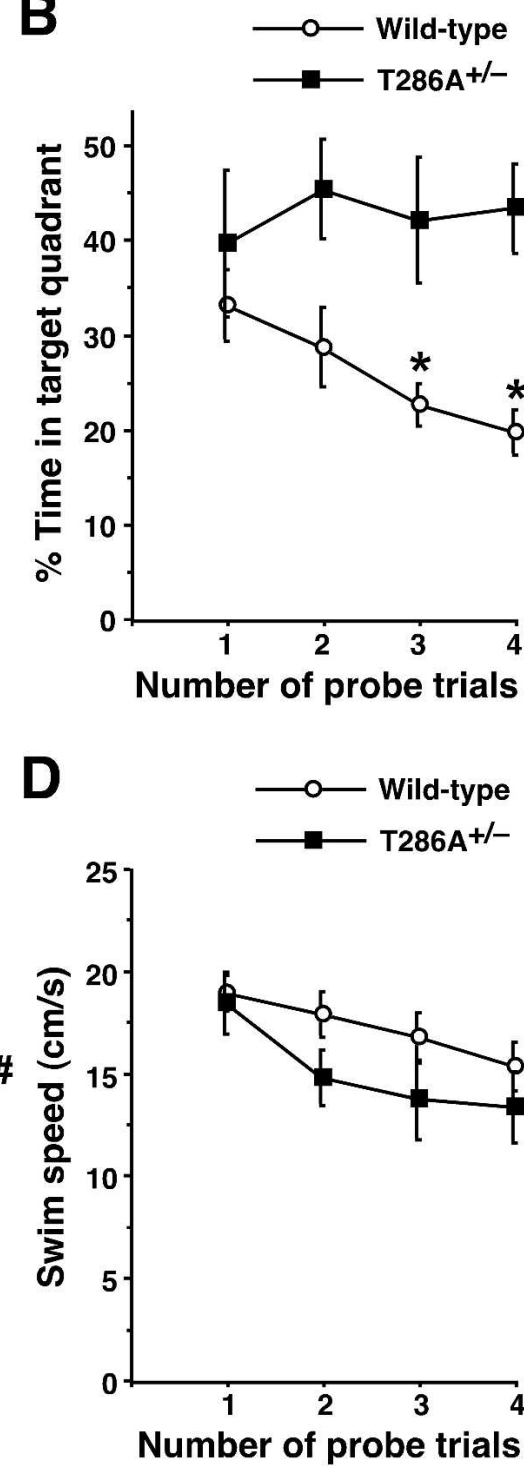

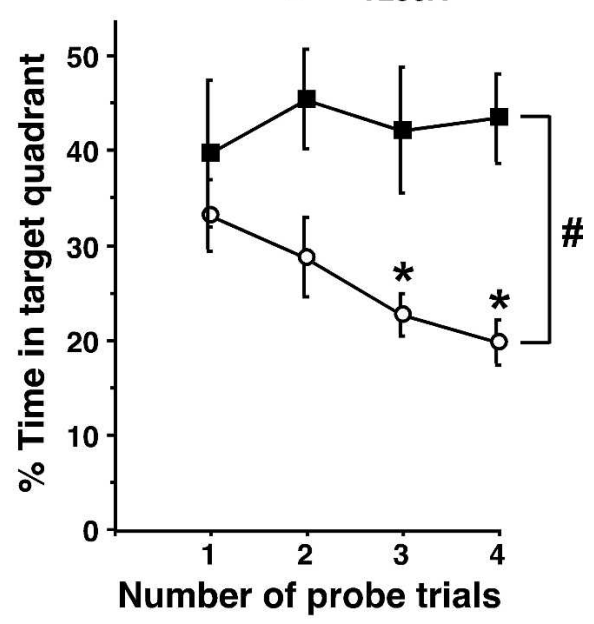

-

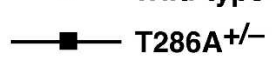

25

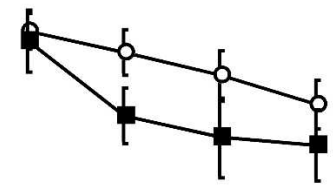

Figure 2. The $\alpha \mathrm{CaMKII}{ }^{\mathrm{T} 286 \mathrm{~A}+/-}$ mutation interferes with extinction of spatial memory in the water maze. $(A) \alpha$ CaMKII ${ }^{\mathrm{T286A+/-}}$ mice $(n=7)$ and wild-type littermates $(n=15)$ were trained with six trials (three blocks of two trials) per day for $5 \mathrm{~d}$ in the hidden platform version of the Morris water maze. Latencies to reach the escape platform are plotted across training days. $(B, C)$ Twenty-four hours after the last training trial, mice received four consecutive probe trials in which the platform was removed from the pool. Wild-type control mice exhibited significant reductions in preference for the original target location as assessed by the percent time in the target quadrant $(B)$ and proximity to the target (C). $\left[{ }^{*}\right] P<0.05$ vs. probe trial 1 . Note that $\alpha$ CaMKIII $286 \mathrm{~A}+/-$ mutants showed no changes in spatial memory measures through the probe trials and exhibited significantly higher levels of selective search for the platform position during extinction as compared with those of wild-type controls. $\left(^{\#}\right) P<0.05$ vs. wild-type. $(D)$ The average swim speed neither significantly changed during the extinction trials nor differed between $\alpha \mathrm{CaMKII}{ }^{\mathrm{T} 286 \mathrm{~A}+/-}$ mutants and wild-type controls. All data are presented as mean \pm SEM.

measure of spatial memory (Fig. 2C), we confirmed that extinction occurred in wild-type mice, as assessed by significant increases in proximity to the accurate platform position $\left(F_{(3,56)}=\right.$ $3.45, P<0.05)$, whereas $\alpha \mathrm{CaMKII}^{\mathrm{T} 286 \mathrm{~A}+/-}$ mutants showed no change in proximity through four consecutive probe trials $\left(F_{(3,24)}=0.36, P>0.05\right)$ and extinction was significantly prohibited in this mutant $\left(F_{(1,20)}=12.04, P<0.05\right)$. During the extinction trials, neither significant floating behavior nor reductions in the average swim speed were observed in $\alpha \mathrm{CaMKII}{ }^{\mathrm{T} 286 \mathrm{~A}+/-}$ mutants $\left(F_{(3,24)}=2.00, P>0.05\right)$ or wild-type control mice $\left(F_{(3,56)}=1.98\right.$, $P>0.05)$, and there was no difference in swim speed between both groups $\left(F_{(1,20)}=1.71, P>0.05\right)$ (Fig. $2 \mathrm{D})$. Therefore, the $\alpha \mathrm{CaMKII}^{\mathrm{T} 286 \mathrm{~A}+/-}$ mutation specifically interfered with extinction of spatial memory without affecting swim performance by itself in the water maze.

$\alpha \mathrm{CaMKII}^{\mathrm{T} 286 \mathrm{~A}+\text { /- }}$ mutation blocks new learning but not unlearning mechanisms of fear memory extinction

Different mechanisms of extinction are suggested to occur depending upon the length of intervals between initial learning and extinction sessions: Extinction after longer intervals may more preferentially trigger new learning mechanisms, while shorter intervals may result in unlearning processes (Cain et al. 2005; Mao et al. 2006; Myers et al. 2006). To address the roles of $\alpha$ CaMKII signaling in the two distinct processes of extinction, mice were subjected to a single but longer re-exposure to the conditioning context in the absence of foot shock, which has been reported to favor the development of rapid and dramatic extinction of contextually conditioned fear (Suzuki et al. 2004; Isiegas et al. 2006). Consistent with these findings, we also found that a single 30-min re-exposure of wild-type control mice to the chamber $24 \mathrm{~h}$ after training with one CS-US pairing resulted in a significant reduction of contextual freezing within the long extinction session $\left(F_{(4,105)}=6.99\right.$, $P<0.05$ ) (Fig. 3A). A form of new learning that underlies extinction is accounted for by the fact that spontaneous recovery of extinguished fear responses occurs with the passage of time following extinction in the absence of any further training (Myers and Davis 2002, 2007). Importantly, while wild-type mice showed significantly lower levels of freezing during the last 6-min period of extinction session as compared with the first 6-min period, comparable contextual freezing reappeared in a test for spontaneous recovery given $21 \mathrm{~d}$ after extinction $\left(F_{(2,63)}=11.30, P<0.05\right)$ (Fig. 3B). Since the original fear memory remained intact, this experimental protocol for extinction initiated $24 \mathrm{~h}$ after contextual conditioning engaged new learning of inhibition.

$\alpha \mathrm{CaMKII}^{\mathrm{T} 286 \mathrm{~A}+/-}$ mutant mice exhibited robust contextual freezing during the first $6 \mathrm{~min}$ of extinction that was indistinguishable from that of wild-type controls $\left(F_{(1,39)}=0.28, P>0.05\right)$, but they showed no significant reduction in freezing through the 30-min extinction session conducted $24 \mathrm{~h}$ after conditioning $\left(F_{(4,90)}=1.04, P>0.05\right)$, presenting a contrast to the performance of wild-type mice (Fig. 3A). Notably, freezing levels of $\alpha \mathrm{CaMKII}^{\mathrm{T} 286 \mathrm{~A}+/-}$ mice observed during the final 6-min period of the extinction session were significantly higher than those of 
A

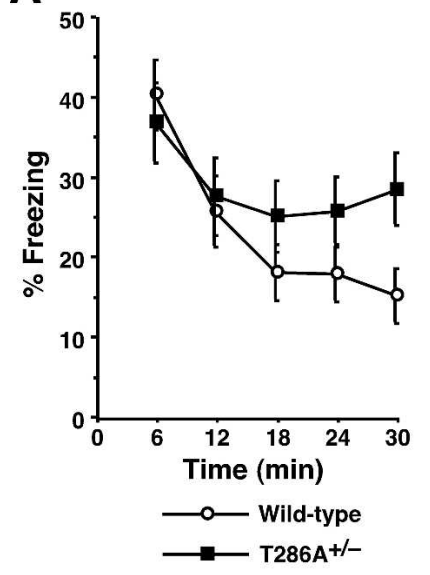

B

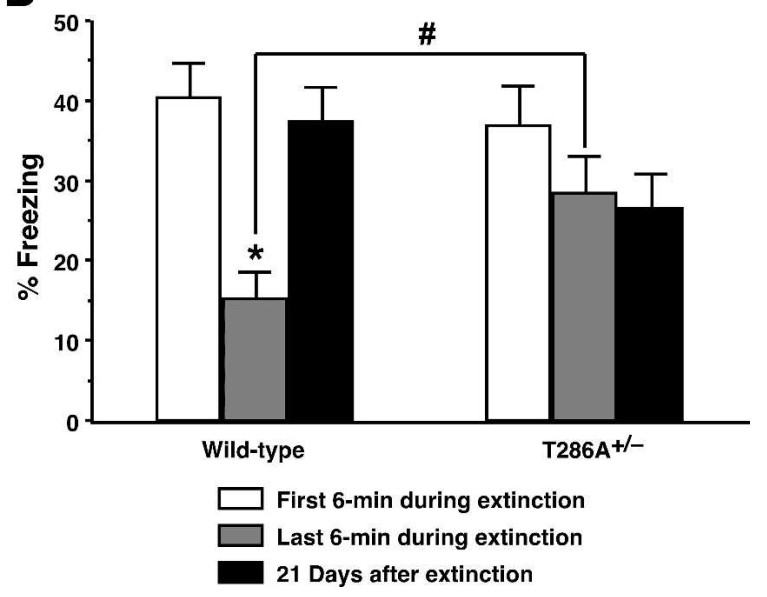

Figure 3. The $\alpha \mathrm{CaMKII}{ }^{\mathrm{T} 286 \mathrm{~A}+/-}$ mutation interferes with new learning mechanisms for fear memory extinction. $(A) \alpha$ CaMKII $^{\mathrm{T} 286 \mathrm{~A}+/-}$ mice $(n=19)$ and wild-type littermates $(n=22)$ were trained with one CS-US pairing for contextual fear conditioning. Mice were subjected to a single 30-min re-exposure to the conditioning context $24 \mathrm{~h}$ after training. Levels of freezing are plotted every 6 min through the 30-min extinction session. Wild-type mice, but not $\alpha \mathrm{CaMKII}{ }^{\mathrm{T} 286 \mathrm{~A}+/}-$ mutants, exhibited significant reductions in freezing within the 30-min extinction session. (B) In wild-type control mice, levels of contextual freezing were significantly reduced during the last 6-min period compared with the first 6 min of the extinction session, and spontaneous recovery of the extinguished fear memory was observed 21 d later. $\left(^{*}\right) P<0.05$ vs. the first $6 \mathrm{~min}$ and $21 \mathrm{~d}$ after extinction. Note that $\alpha \mathrm{CaMKII}{ }^{\mathrm{T} 286 \mathrm{~A}+/-}$ mutants showed no significant changes in freezing throughout testing and exhibited significantly higher levels of contextual freezing during the last $6 \mathrm{~min}$ of extinction as compared with those of wild-type controls ( $\left[{ }^{\#}\right] P<0.05$ vs. wild-type). All data are presented as mean \pm SEM.

wild-type littermate mice $\left(F_{(1,39)}=5.70, P<0.05\right)$ (Fig. 3B) and were not different from levels of freezing in $\alpha \mathrm{CaMKII}^{\mathrm{T} 286 \mathrm{~A}+/-}$ mice during the initial 6 min of extinction or during the test for spontaneous recovery conducted $21 \mathrm{~d}$ later $\left(F_{(2,54)}=1.39\right.$, $P>0.05)$. Taken together, these results showed that the $\alpha \mathrm{CaMKII}^{\mathrm{T} 286 \mathrm{~A}+/-}$ mutation interfered with new learning mechanisms underlying extinction of contextual fear memory without affecting initial contextual learning.

On the other hand, neither wild-type mice $\left(F_{(4,95)}=1.56\right.$, $P>0.05)$ nor $\alpha$ CaMKII $^{\mathrm{T} 286 \mathrm{~A}+/-}$ mutants $\left(F_{(4,115)}=0.79, P>0.05\right)$ showed a significant within-session reduction in contextual freezing when the 30-min extinction session was given $15 \mathrm{~min}$ after training (Fig. 4A). Since similar levels of freezing were observed throughout the extinction session, including the first 6 -min period in $\alpha \mathrm{CaMKII}^{\mathrm{T} 286 \mathrm{~A}+/-}$ and wild-type control groups (Fig. 4A,C), we tested a subset of mice $1 \mathrm{~d}$ later to clarify whether conditioned fear memory was extinguished (Fig. 4B). Significantly lower levels of freezing during this post-extinction test as compared with the first $6 \mathrm{~min}$ of the extinction session were observed in wild-type control mice $\left(F_{(2,57)}=8.72, P<0.05\right)$ and $\alpha$ CaMKII $^{\mathrm{T} 286 \mathrm{~A}+/-}$ mutants $\left(F_{(2,69)}=13.78, P<0.05\right)$, and, more importantly, the freezing levels of both groups remained significantly lower $21 \mathrm{~d}$ after the extinction session, representing no spontaneous recovery of extinguished memory. However, it is possible that the additional exposure to the conditioning chamber $1 \mathrm{~d}$ after extinction prevented spontaneous recovery. To address this possibility, we tested the other set of mice for spontaneous recovery $21 \mathrm{~d}$ after the 30 -min extinction session without any sessions intervening between them (Fig. 4D). While no within-session extinction was observed again in wild-type controls $\left(F_{(4,55)}=0.68, P>0.05\right)$ or $\alpha \mathrm{CaMKII}^{\mathrm{T} 286 \mathrm{~A}+/-}$ mice $\left(F_{(4,75)}=0.69, P>0.05\right)$ during 30-min exposure to the chamber given 15 min post-training (Fig. 4C), their freezing levels $21 \mathrm{~d}$ later were significantly lower than those of the first 6-min period in wild-type mice $\left(F_{(1,22)}=10.98, P<0.05\right)$ and $\alpha \mathrm{CaMKII}^{\mathrm{T} 286 \mathrm{~A}+/-}$ mutants $\left(F_{(1,30)}=24.43, P<0.05\right)$ (Fig. $\left.4 \mathrm{D}\right)$. Thus, we concluded that extinction initiated $15 \mathrm{~min}$ after training was devoid of spontaneous recovery of contextual memory in both wild-type control and $\alpha \mathrm{CaMKII}^{\mathrm{T} 286 \mathrm{~A}+/-}$ mutant mice.

It should be noted that the shortinterval group of wild-type mice produced poorer extinction (Fig. 4), as compared with the long-interval group that received the same 30-min extinction session $24 \mathrm{~h}$ after contextual training and exhibited a robust within-session extinction (Fig. 3A). However, this did not appear to account for the lack of recovery in the short-interval extinction group, since poorer extinction was not associated with poorer retention of extinction but rather enduring extinction. In the first set of experiments (Fig. 4B), $\alpha \mathrm{CaMKII}^{\mathrm{T} 286 \mathrm{~A}+/-}$ mutants showed significantly lower levels of freezing as compared to wild-type controls during the memory testing $1 \mathrm{~d}\left(F_{(1,42)}=29.14\right.$, $P<0.05)$ and $21 \mathrm{~d}\left(F_{(1,42)}=11.42\right.$, $P<0.05)$ after mice were exposed to a 30-min extinction session 15 min posttraining. However, this was likely due to slightly lower levels of freezing during the first $6 \mathrm{~min}$ of extinction in $\alpha \mathrm{CaMKII}^{\mathrm{T} 286 \mathrm{~A}+/-}$ mutants (although statistically not significant; $F_{(1,42)}=3.54, P=0.07$ ), and no difference in freezing was observed between $\alpha \mathrm{CaMKII}^{\mathrm{T} 286 \mathrm{~A}+/-}$ and wildtype mice during the first $6 \mathrm{~min}$ of the extinction session $\left(F_{(1,26)}=0.45, P=0.51\right)$ or during memory testing $21 \mathrm{~d}$ postextinction $\left(F_{(1,26)}=0.12, P=0.74\right)$ in the second set of experiments (Fig. 4D). Obviously, in contrast to the impacts on new learning mechanisms of delayed extinction $24 \mathrm{~h}$ post-training that were followed by spontaneous recovery (Fig. 3), the $\alpha \mathrm{CaMKII}^{\mathrm{T} 286 \mathrm{~A}+/-}$ mutation did not inhibit the short-interval extinction, which was initiated 15 min post-training and showed no signs of spontaneous recovery (Fig. 4). Collectively, our results strongly supported the idea that different mechanisms are recruited during memory extinction at shorter and longer time points after training (Cain et al. 2005; Mao et al. 2006; Myers et al. 2006).

\section{Discussion}

Extinction appears to rely on similar molecular pathways that are responsible for initial learning processes (Myers and Davis 2002, 2007), while evidence is also emerging that extinction may engage different mechanisms (Lattal and Abel 2001; Cain et al. 2002; Marsicano et al. 2002; Isiegas et al. 2006). We investigated the role of $\alpha$ CaMKII, a key molecular determinant of memory formation (Irvine et al. 2006), in extinction of contextual fear and spatial memories by testing how a heterozygous T286A point mutation at the autophosphorylation site of this kinase $\left(\alpha \mathrm{CaMKII}^{\mathrm{T} 286 \mathrm{~A}+/-}\right)$ affects the mechanisms that extinguish memories. Although mice that are homozygous for the $\alpha$ CaMKII $^{\mathrm{T} 286 \mathrm{~A}}$ mutation and deficient in autophosphorylation exhibit impairments in contextual fear conditioning and spatial learning in the water maze (Giese et al. 1998; Ohno et al. 2002, 2005, 2006; Need and Giese 2003; Irvine et al. 2005), $\alpha \mathrm{CaMKII}^{\mathrm{T} 286 \mathrm{~A}+/-}$ mice were normal in the formation of contextual and spatial memories tested $24 \mathrm{~h}$ after training. Remarkably, the $\alpha \mathrm{CaMKII}{ }^{\mathrm{T} 286 \mathrm{~A}+/-}$ mutation prevented extinction of contex- 
A

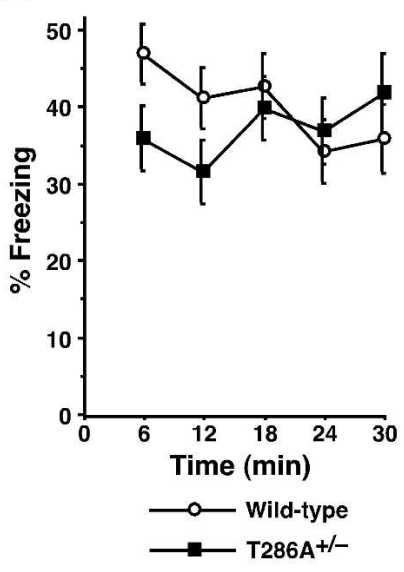

B

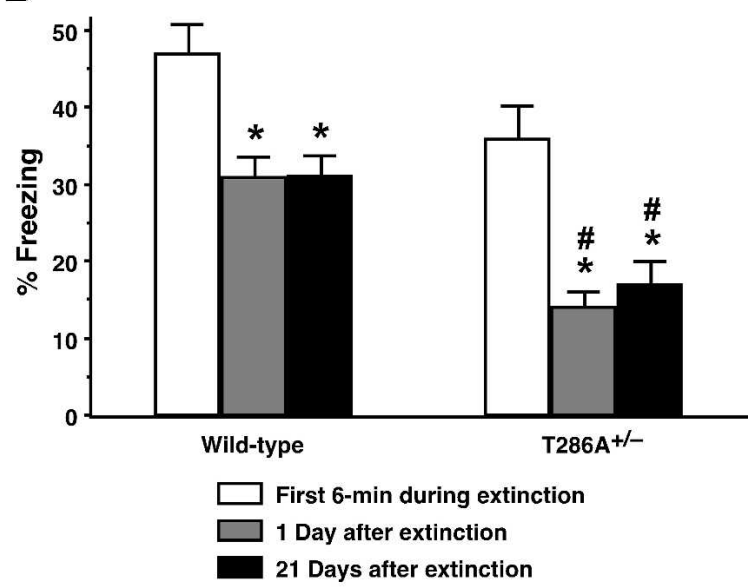

C

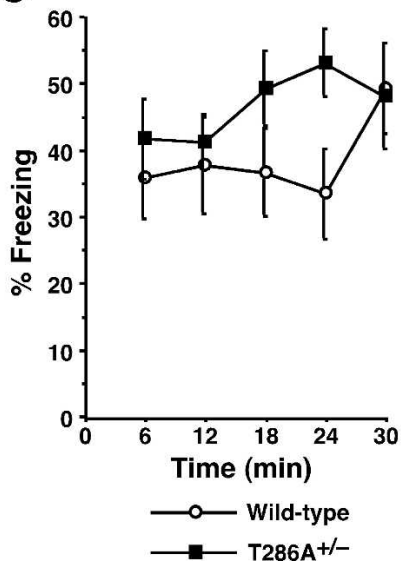

D

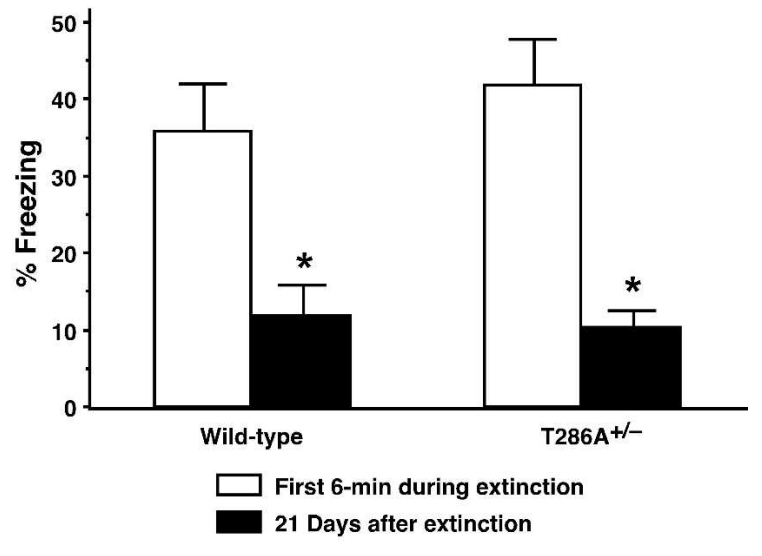

Figure 4. $\alpha \mathrm{CaMKII}{ }^{\mathrm{T} 286 \mathrm{~A}+/-}$ mutation does not interfere with unlearning mechanisms for fear memory extinction. $(A) \alpha \mathrm{CaMKII}{ }^{\mathrm{T} 286 \mathrm{~A}+/-}$ mice $(n=24)$ and wild-type littermates $(n=20)$ were trained with one CS-US pairing for contextual fear conditioning. Mice were subjected to a single 30-min re-exposure to the conditioning context 15 min after training. Levels of freezing are plotted every 6 min through the 30 -min extinction session. Neither wild-type mice nor $\alpha$ CaMKII ${ }^{\text {286A+1- }}$ mutants exhibited significant reductions in freezing within the 30-min extinction session. (B) Both wild-type control mice and $\alpha \mathrm{CaMKII}^{\mathrm{T} 286 \mathrm{~A}+/-}$ mutants showed significantly lower levels of contextual freezing during the test session given $1 \mathrm{~d}$ after the 30-min re-exposure, as compared with the first 6 min of the extinction session. $\left.{ }^{*}\right) P<0.05$ vs. the first $6 \mathrm{~min}$. Furthermore, neither group exhibited spontaneous recovery of the extinguished fear memory when tested $21 \mathrm{~d}$ later. Significant differences in freezing levels between $\alpha \mathrm{CaMKII}{ }^{\mathrm{T} 286 \mathrm{~A}+/-}$ mice and wild-type controls were observed during memory tests given both $1 \mathrm{~d}$ and $21 \mathrm{~d}$ after extinction. $\left(^{\#}\right) P<0.05$ vs. wild-type. $(C, D)$ Separate groups of $\alpha \mathrm{CaMKII}^{\mathrm{T} 286 \mathrm{~A}+/-}(n=16)$ and wild-type $(n=12)$ mice were subjected to the 30 -min extinction session 15 min after training $(C)$ and tested for spontaneous recovery $21 \mathrm{~d}$ later without any intervening sessions $(D) .\left(^{*}\right) P<0.05$ vs. the first $6 \mathrm{~min}$. All data are presented as mean \pm SEM.

tual fear and spatial memories when the mice were repeatedly subjected to the contextual CS-alone sessions or exposed to the water maze pool in the absence of the platform. Therefore, these findings indicate that both initial learning and the development of memory extinction require the activation of $\alpha$ CaMKII through its autophosphorylation, but extinction processes are more susceptible to partial disruption of $\alpha$ CaMKII signaling due to the heterozygous T286A mutation and place higher demands on intact $\alpha$ CaMKII function as compared with memory formation.

It is hypothesized that the length of time between the initial training and extinction sessions may be a determinant of neural mechanisms involved in extinguishing original memory (Cain et al. 2005; Mao et al. 2006; Myers et al. 2006; for review, see Myers and Davis 2007). In particular, Myers et al. (2006) recently tested this hypothesis by giving different groups of rats an extinction session at different time points ranging from $10 \mathrm{~min}$ to $72 \mathrm{~h}$ after acquisition and evaluated their susceptibility to recovery of conditioned fear through reinstatement, renewal, and spontaneous recovery $21 \mathrm{~d}$ later. They demonstrated that rats extinguished $24-72 \mathrm{~h}$ following conditioning exhibit moderate to strong recovery that provides evidence for new learning accounts of extinction, while rats extinguished $10 \mathrm{~min}$ to $1 \mathrm{~h}$ after acquisition exhibit little or no recovery, representing erasure mechanisms of conditioned fear. New learning accounts of extinction involve the formation of a second, inhibitory association whose effect is opposite to the excitatory association between representations of the CS and US during acquisition and renders the CS no longer capable of evoking fear responses. It is conceivable that this inhibitory association is generally more labile or subject to disruption than initial excitatory associations and thus may be lost during the recovery processes of fear memory following extinction (Myers and Davis 2002, 2007). Consistent with these views, we found that wild-type control mice, re-exposed to the chamber for $30 \mathrm{~min} 24 \mathrm{~h}$ after acquisition, exhibit new learning mechanisms of extinction, since they showed spontaneous recovery of contextually conditioned fear responses that were measured $21 \mathrm{~d}$ after extinction.

Importantly, our results demonstrated that the $\alpha \mathrm{CaMKII}{ }^{\mathrm{T} 286 \mathrm{~A}+/-}$ mutation significantly and specifically impairs the new learning processing of fear memory extinction tested $24 \mathrm{~h}$ after training with a single CS-US pairing without affecting initial fear learning, suggesting a critical role of $\alpha$ CaMKII signaling in extinguishing memories through new learning mechanisms. It should be noted that a homozygous $\alpha$ CaMKII ${ }^{\mathrm{T} 286 \mathrm{~A}}$ mutation abolishes NMDA-receptor-dependent LTP at hippocampal Schaffer collateral-CA1 synapses (Giese et al. 1998; Ohno et al. 2002; Cooke et al. 2006) and impairs contextual conditioning after a single training trial (Irvine et al. 2005; Ohno et al. 2005), while LTP is only attenuated, and considerable levels of LTP remain in the heterozygotes (Ohno et al. 2002). It is reasonable to suppose that partial reductions in LTP may impact new learning mechanisms of extinction but the residual level of LTP may be enough to sustain initial fear learning in $\alpha \mathrm{CaMKII}{ }^{\mathrm{T} 286 \mathrm{~A}+/-}$ mutants, since the inhibitory association is formed by re-exposure to the context CS alone during extinction and thus, is more vulnerable to disruptions as compared with the excitatory association with CS-US pairing during fear memory acquisition.

On the other hand, a single 30-min re-exposure of wild-type control mice to the conditioning chamber 15 min after contextual training caused less extinction of fear memory compared with that given $24 \mathrm{~h}$ after conditioning, since it showed no 
within-session extinction and produced significant but only limited levels of reduction in freezing during a post-extinction test occurring $24 \mathrm{~h}$ later. Similar differences in the efficacy of shortinterval versus long-interval extinction have been reported previously (Cain et al. 2005; Cammarota et al. 2005; Maren and Chang 2006; Myers et al. 2006). Of particular interest, Maren and Chang (2006) compared the 15-min and 24-h interval extinctions after tone fear conditioning in rats, and demonstrated that both extinction procedures acutely suppressed fear memories, but shorter-interval extinction was less effective in producing long-term suppression of conditioned fear ( $48 \mathrm{~h}$ after extinction). Therefore, the results suggest that recent fear memory is more resistant to extinction. However, this difference does not seem to reflect the conditioning-extinction interval per se, but rather is due to the higher levels of freezing at the outset of shorterinterval extinction training. In fact, the investigators demonstrated that reducing the number of conditioning trials and thus decreasing levels of fear at the time of extinction (15 min posttraining) enabled animals to exhibit the long-term retention of extinction, which lasted at least for a week without spontaneous recovery. The present study similarly demonstrated that extinction of contextual fear memory at a shorter time point (15 min) after initial training, as compared with that at a longer time point ( $24 \mathrm{~h}$ ), becomes less complete but more resistant to spontaneous recovery. Our results are also consistent with recent findings that animals that underwent extinction 10-60 min after conditioning lacked spontaneous recovery of memory, as measured by fearpotentiated acoustic startle responses, in contrast to the animals extinguished 24-72 h after training (Myers et al. 2006).

What mechanisms may account for the short-interval extinction, which is less susceptible to spontaneous recovery of original memories than is long-interval extinction? Psychological theories have described extinction as "unlearning," in which the excitatory association between CS and US mediating conditioned responses is weakened and ultimately lost (Rescorla and Wagner 1972; Wagner and Rescorla 1972; for review, see Myers and Davis 2007). More recent evidence points to the importance of the timing of extinction relative to conditioning in determining the nature of extinction. Given that recovery effects serve as the impetus for new learning accounts of extinction (Myers and Davis 2002, 2007), the absence of spontaneous recovery implies the possibility that erasure may be a plausible mechanism underlying short-interval extinction (Myers et al. 2006). Importantly, this idea is strongly supported by recent neurobiological observations (Cain et al. 2005; Mao et al. 2006). For example, fear extinction initiated immediately after acquisition is insensitive to the L-type voltage-gated calcium channel (L-VGCC) blocker nifedipine, whereas delayed extinction is impaired by nifedipine (Cain et al. 2005). Therefore, the L-VGCC dependence of extinction is related to the maturity or consolidation state of the acquired memory. The investigators suggested that extinction training may act to weaken the excitatory CS-US association formed during acquisition in an L-VGCC-independent manner when fear memory has not yet fully consolidated at shorter intervals after acquisition, probably via a mechanism corresponding to depotentiation or long-term depression (LTD). Consistent with this hypothesis, extinction training applied $1 \mathrm{~h}$ after acquisition reversed the fear conditioning-induced synaptic insertion of AMPA-type glutamate receptors (a putative molecular mechanism for erasure of fear memories), whereas this reversal did not occur when extinction was started $24 \mathrm{~h}$ after training (Mao et al. 2006). The present study demonstrated that the $\alpha \mathrm{CaMKII}^{\mathrm{T} 286 \mathrm{~A}+/-}$ mutation does not affect short-interval extinction, which is initiated 15 min after contextual conditioning, as opposed to interfering with new learning mechanisms during delayed extinction $24 \mathrm{~h}$ post-training. Therefore, our observations further support the view that distinct molecular mechanisms underlie short- and long-interval extinction of memory. It seems reasonable to speculate that the incomplete consolidation state $15 \mathrm{~min}$ after training may be preferentially subjected to an $\alpha$ CaMKII-independent unlearning processing of fear memory (e.g., depotentiation or LTD) rather than new learning of inhibition, which proceeds via $\alpha$ CaMKII-mediated mechanisms and is crucial for extinguishing well-consolidated memory $24 \mathrm{~h}$ after conditioning.

Taken collectively, our results suggest that $\alpha$ CaMKIIdependent signaling is specifically involved in mediating a form of new learning that counteracts the expression of original memories during long-interval extinction, whereas $\alpha$ CaMKII function does not contribute to erasure processing of memories at a labile state during short-interval extinction. The data presented here favor the notion that the molecular machinery may differentially participate in extinguishing memories depending on the timing of extinction, although further studies will be required to fully understand the neurobiological basis of both types of memory extinction.

\section{Materials and Methods}

\section{Mice}

The generation of the $\alpha \mathrm{CaMKII}^{\mathrm{T} 286 \mathrm{~A}}$ mutant mice was described previously (Giese et al. 1998). The heterozygous $\alpha$ CaMKII $^{\mathrm{T} 286 \mathrm{~A}}$ population was backcrossed more than 15 generations into the C57BL/6N background from the original 129/B6 background. The resultant $\alpha$ CaMKII ${ }^{\mathrm{T} 286 \mathrm{~A}+/-}$ mutants at $3-5$ mo of age were used for the experiments, and wild-type littermate mice served as controls. At 3-4 wk postnatally, the mice were weaned and genotyping was performed by PCR analysis of tail DNA. All experiments were done blind with respect to the genotype of the mice and were conducted with the approval of the Nathan Kline Institute Animal Care and Use Committee.

\section{Fear conditioning}

Contextual fear conditioning was tested as described previously (Ohno et al. 2001, 2005). The experiments were performed using four standard conditioning chambers, each of which was housed in a soundproof isolation cubicle and equipped with a stainlesssteel grid floor connected to a solid-state shock scrambler. Each scrambler was connected to an electronic constant-current shock source that was controlled via an interface connected to a Windows XP computer running FreezeFrame software (Coulbourn Instruments). A digital camera was mounted on the steel ceiling of each chamber, and video signals were sent to the same computer for analysis. During training, all mice that were going to be subjected to extinction later were placed in the conditioning chamber for $3 \mathrm{~min}$ and then exposed to a foot shock $(1.0 \mathrm{~mA}, 2$ sec). After the shock delivery, mice were left in the chamber for another $30 \mathrm{sec}$. Contextual fear memory was measured by scoring freezing behavior (the absence of all but respiratory movement) when the mice were placed back into the same conditioning chamber. We also assessed freezing before and after foot shock was delivered during training. The automated FreezeFrame system digitizes the video signal at $4 \mathrm{~Hz}$ and compares movement frame by frame to score the amount of freezing.

During the repeated extinction sessions, mice were reexposed to the conditioning chamber in the absence of foot shock for 6 min per day for five consecutive days, staring $24 \mathrm{~h}$ after contextual fear training, and levels of freezing were assessed. To investigate new learning and unlearning mechanisms of fear memory extinction, different sets of mice received a single 30min re-exposure to the chamber without foot shock $24 \mathrm{~h}$ and 15 min after contextual conditioning, respectively. Since significant within-session reductions in contextual freezing were not observed in the short-interval extinction groups, extinction was evaluated by comparing the freezing when these mice were reexposed to the conditioning chamber for $3 \mathrm{~min}, 24 \mathrm{~h}$ after the 30-min extinction session. As a control, a subset of mice that were subjected to 30-min extinction $15 \mathrm{~min}$ after training did not 
receive the additional 3-min exposure to the chamber $24 \mathrm{~h}$ postextinction. Twenty-one days after extinction, all mice were reexposed to the training context for $3 \mathrm{~min}$ to test spontaneous recovery of extinguished fear memory.

\section{Morris water maze}

The basic water maze protocol and apparatus have been described previously (Bourtchuladze et al. 1994; Ohno et al. 2005). Before training, each mouse was handled for 2 min every day for $7-10 \mathrm{~d}$. The pool was $1.2 \mathrm{~m}$ in diameter and was made of white plastic. The water was maintained at $24^{\circ} \mathrm{C} \pm 1^{\circ} \mathrm{C}$ throughout the experiments and was made opaque with nontoxic white paint to hide the white and square escape platform $(10 \mathrm{~cm} \times 10 \mathrm{~cm})$. During training, the escape platform was submerged $(1 \mathrm{~cm})$ below the water surface and remained in the same position in the pool for a particular mouse, but groups of animals were trained with different platform positions to avoid quadrant biases.

Every training trial started with the mouse on the platform for $30 \mathrm{sec}$. The mouse was placed into the water facing the wall of the pool and was allowed to search for the platform. The starting position varied among four locations in a pseudorandom manner for each trial. The mice received six trials per day for $5 \mathrm{~d}$ (three blocks of two trials; 1-min inter-trial intervals, 1-h interblock intervals). The trial ended either when an animal climbed onto the platform or when a maximum of $60 \mathrm{sec}$ elapsed. The mouse was placed on the platform for $30 \mathrm{sec}$ at the end of each trial. Twenty-four hours after the last training trial, all mice were given four consecutive 60 -sec probe trials (30-min intervals) in which they swam in the pool in the absence of the platform. The data collection and analysis were performed using a digital tracking device (HVS Image).

\section{Statistical analysis}

The significance of differences between the groups was determined by a one-way ANOVA or by a two-way ANOVA with repeated measures, and post-hoc Fisher's PLSD tests were performed when appropriate.

\section{Acknowledgment}

This work was supported by a National Institute of Mental Health grant (R01 MH067251) to M.O.

\section{References}

Bevilaqua, L.R., Bonini, J.S., Rossato, J.I., Izquierdo, L.A., Cammarota, M., and Izquierdo, I. 2006. The entorhinal cortex plays a role in extinction. Neurobiol. Learn. Mem. 85: 192-197.

Bourtchuladze, R., Frenguelli, B., Blendy, J., Cioffi, D., Schutz, G., and Silva, A.J. 1994. Deficient long-term memory in mice with a targeted mutation of the cAMP-responsive element-binding protein. Cell 79: 59-68.

Cain, C.K., Blouin, A.M., and Barad, M. 2002. L-type voltage-gated calcium channels are required for extinction, but not for acquisition or expression, of conditional fear in mice. J. Neurosci. 22: 9113-9121.

Cain, C.K., Godsil, B.P., Jami, S., and Barad, M. 2005. The L-type calcium channel blocker nifedipine impairs extinction, but not reduced contingency effects, in mice. Learn. Mem. 12: 277-284.

Cammarota, M., Bevilaqua, L.R., Rossato, J.I., Ramirez, M., Medina, J.H., and Izquierdo, I. 2005. Relationship between short- and long-term memory and short- and long-term extinction. Neurobiol. Learn. Mem. 84: $25-32$.

Cooke, S.F., Wu, J., Plattner, F., Errington, M., Rowan, M., Peters, M., Hirano, A., Bradshaw, K.D., Anwyl, R., Bliss, T.V., et al. 2006. Autophosphorylation of $\alpha$ CaMKII is not a general requirement for NMDA receptor-dependent LTP in the adult mouse. J. Physiol. 574: $805-818$.

Elgersma, Y., Sweatt, J.D., and Giese, K.P. 2004. Mouse genetic approaches to investigating calcium/calmodulin-dependent protein kinase II function in plasticity and cognition. J. Neurosci. 24: $8410-8415$.

Fukunaga, K., Muller, D., and Miyamoto, E. 1995. Increased phosphorylation of $\mathrm{Ca}^{2+} /$ calmodulin-dependent protein kinase II and its endogenous substrates in the induction of long-term potentiation. J. Biol. Chem. 270: 6119-6124.

Giese, K.P., Fedorov, N.B., Filipkowski, R.K., and Silva, A.J. 1998. Autophosphorylation at $\mathrm{Thr}^{286}$ of the $\alpha$ calcium-calmodulin kinase
II in LTP and learning. Science 279: 870-873.

Irvine, E.E., Vernon, J., and Giese, K.P. 2005. $\alpha$ CaMKII autophosphorylation contributes to rapid learning but is not necessary for memory. Nat. Neurosci. 8: 411-412.

Irvine, E.E., von Hertzen, L.S., Plattner, F., and Giese, K.P. 2006. $\alpha$ CaMKII autophosphorylation: A fast track to memory. Trends Neurosci. 29: 459-465.

Isiegas, C., Park, A., Kandel, E.R., Abel, T., and Lattal, K.M. 2006. Transgenic inhibition of neuronal protein kinase A activity facilitates fear extinction. I. Neurosci. 26: 12700-12707.

Lattal, K.M. and Abel, T. 2001. Different requirements for protein synthesis in acquisition and extinction of spatial preferences and context-evoked fear. J. Neurosci. 21: 5773-5780.

Lattal, K.M., Mullen, M.T., and Abel, T. 2003. Extinction, renewal, and spontaneous recovery of a spatial preference in the water maze. Behav. Neurosci. 117: 1017-1028.

Lisman, J., Schulman, H., and Cline, H. 2002. The molecular basis of CaMKII function in synaptic and behavioural memory. Nat. Rev. Neurosci. 3: 175-190.

Mao, S.C., Hsiao, Y.H., and Gean, P.W. 2006. Extinction training in conjunction with a partial agonist of the glycine site on the NMDA receptor erases memory trace. J. Neurosci. 26: 8892-8899.

Maren, S. and Chang, C.H. 2006. Recent fear is resistant to extinction. Proc. Natl. Acad. Sci. 103: 18020-18025.

Marsicano, G., Wotjak, C.T., Azad, S.C., Bisogno, T., Rammes, G., Cascio, M.G., Hermann, H., Tang, J., Hofmann, C., Zieglgansberger, W., et al. 2002. The endogenous cannabinoid system controls extinction of aversive memories. Nature 418: 530-534.

Miller, S.G. and Kennedy, M.B. 1986. Regulation of brain type II $\mathrm{Ca}^{2+} /$ calmodulin-dependent protein kinase by autophosphorylation: $\mathrm{A} \mathrm{Ca}^{2+}$-triggered molecular switch. Cell 44: 861-870.

Myers, K.M. and Davis, M. 2002. Behavioral and neural analysis of extinction. Neuron 36: 567-584.

Myers, K.M. and Davis, M. 2007. Mechanisms of fear extinction. Mol. Psychiatry 12: 120-150.

Myers, K.M., Ressler, K.J., and Davis, M. 2006. Different mechanisms of fear extinction dependent on length of time since fear acquisition. Learn. Mem. 13: 216-223.

Need, A.C. and Giese, K.P. 2003. Handling and environmental enrichment do not rescue learning and memory impairments in $\alpha$ CamKII $^{\mathrm{T} 286 \mathrm{~A}}$ mutant mice. Genes Brain Behav. 2: 132-139.

Ohno, M., Frankland, P.W., Chen, A.P., Costa, R.M., and Silva, A.J. 2001. Inducible, pharmacogenetic approaches to the study of learning and memory. Nat. Neurosci. 4: 1238-1243.

Ohno, M., Frankland, P.W., and Silva, A.J. 2002. A pharmacogenetic inducible approach to the study of NMDA/ $\alpha$ CaMKII signaling in synaptic plasticity. Curr. Biol. 12: 654-656.

Ohno, M., Tseng, W., Silva, A.J., and Disterhoft, J.F. 2005. Trace eyeblink conditioning requires the hippocampus but not autophosphorylation of $\alpha$ CaMKII in mice. Learn. Mem. 12: 211-215.

Ohno, M., Sametsky, E.A., Silva, A.J., and Disterhoft, J.F. 2006. Differential effects of $\alpha$ CaMKII mutation on hippocampal learning and changes in intrinsic neuronal excitability. Eur. J. Neurosci. 23: $2235-2240$

Ouyang, Y., Kantor, D., Harris, K.M., Schuman, E.M., and Kennedy, M.B. 1997. Visualization of the distribution of autophosphorylated calcium/calmodulin-dependent protein kinase II after tetanic stimulation in the CA1 area of the hippocampus. J. Neurosci. 17: 5416-5427.

Rescorla, R.A. and Wagner, A.R. 1972. A theory of Pavlovian conditioning: Variations in the effectiveness of reinforcement and nonreinforcement. In Classical conditioning II (eds. A.H. Black and W.F. Prokasy), pp. 64-99. Appleton-Century-Crofts, New York.

Rodrigues, S.M., Farb, C.R., Bauer, E.P., LeDoux, J.E., and Schafe, G.E. 2004. Pavlovian fear conditioning regulates $\mathrm{Thr}^{286}$ autophosphorylation of $\mathrm{Ca}^{2+} /$ calmodulin-dependent protein kinase II at lateral amygdala synapses. J. Neurosci. 24: 3281-3288.

Suzuki, A., Josselyn, S.A., Frankland, P.W., Masushige, S., Silva, A.J., and Kida, S. 2004. Memory reconsolidation and extinction have distinct temporal and biochemical signatures. J. Neurosci. 24: 4787-4795.

Szapiro, G., Vianna, M.R., McGaugh, J.L., Medina, J.H., and Izquierdo, I. 2003. The role of NMDA glutamate receptors, PKA, MAPK, and CAMKII in the hippocampus in extinction of conditioned fear. Hippocampus 13: 53-58.

Tan, S.E. and Liang, K.C. 1996. Spatial learning alters hippocampal calcium/calmodulin-dependent protein kinase II activity in rats. Brain Res. 711: 234-240.

Wagner, A.R. and Rescorla, R.A. 1972. Inhibition in Pavlovian conditioning: Application of a theory. In Inhibition and learning (eds. R.A. Boakes and M.S. Halliday), pp. 301-336. Academic Press, London.

Received April 4, 2008; accepted in revised form August 27, 2008. 


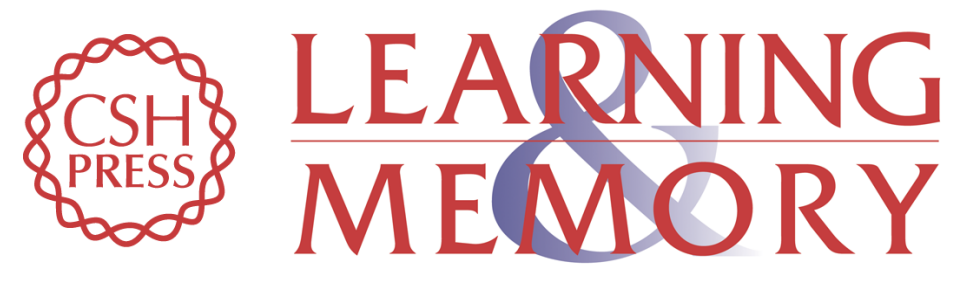

\section{Autophosphorylation of $\alpha$ CaMKII is differentially involved in new learning and unlearning mechanisms of memory extinction}

Ryoichi Kimura, Alcino J. Silva and Masuo Ohno

Learn. Mem. 2008, 15:

Access the most recent version at doi:10.1101//m.1049608

References This article cites 32 articles, 14 of which can be accessed free at: http://learnmem.cshlp.org/content/15/11/837.full.html\#ref-list-1

License

Email Alerting Receive free email alerts when new articles cite this article - sign up in the box at the Service top right corner of the article or click here. 